\title{
Country Differences and Changes in Focus of Scientific Tobacco Control Publications between 2000 and 2012 in Europe
}

Citation for published version (APA):

Willemsen, M. C., \& Nagelhout, G. E. (2016). Country Differences and Changes in Focus of Scientific Tobacco Control Publications between 2000 and 2012 in Europe. European Addiction Research, 22(1), 52-58. https://doi.org/10.1159/000381674

Document status and date:

Published: 01/01/2016

DOI:

10.1159/000381674

Document Version:

Publisher's PDF, also known as Version of record

Document license:

Taverne

Please check the document version of this publication:

- A submitted manuscript is the version of the article upon submission and before peer-review. There can be important differences between the submitted version and the official published version of record.

People interested in the research are advised to contact the author for the final version of the publication, or visit the DOI to the publisher's website.

- The final author version and the galley proof are versions of the publication after peer review.

- The final published version features the final layout of the paper including the volume, issue and page numbers.

Link to publication

\footnotetext{
General rights rights.

- You may freely distribute the URL identifying the publication in the public portal. please follow below link for the End User Agreement:

www.umlib.nl/taverne-license

Take down policy

If you believe that this document breaches copyright please contact us at:

repository@maastrichtuniversity.nl

providing details and we will investigate your claim.
}

Copyright and moral rights for the publications made accessible in the public portal are retained by the authors and/or other copyright owners and it is a condition of accessing publications that users recognise and abide by the legal requirements associated with these

- Users may download and print one copy of any publication from the public portal for the purpose of private study or research.

- You may not further distribute the material or use it for any profit-making activity or commercial gain

If the publication is distributed under the terms of Article 25fa of the Dutch Copyright Act, indicated by the "Taverne" license above, 


\title{
Country Differences and Changes in Focus of Scientific Tobacco Control Publications between 2000 and 2012 in Europe
}

\author{
Marc C. Willemsen ${ }^{a, b}$ Gera E. Nagelhout ${ }^{a, b}$ \\ ${ }^{a}$ Maastricht University (CAPHRI), Department of Health Promotion, Maastricht, and ${ }^{b}$ Dutch Alliance for a Smokefree \\ Society, The Hague, The Netherlands
}

\section{Key Words}

Bibliometrics - Scientific publications - Tobacco control

\begin{abstract}
Background/Aims: The Framework Convention on Tobacco Control (FCTC) stresses the importance of scientific research. We examined the differences between 31 European countries regarding quantity and focus of tobacco control research publications. Methods: PubMed, Web of Science, Scopus, and Psyclnfo were searched for peer-reviewed articles on tobacco, written by European authors, published between 2000 and 2012. For 2000, 2004, 2008, and 2012 we further identified the main focus of the publication. Results: The volume of European tobacco control scientific publications had almost doubled. Scandinavian countries had most publications per inhabitant, while Bulgaria, Cyprus, Estonia, Latvia, Lithuania, Malta, Romania, Slovakia, and Slovenia had relatively little research output. There was a smaller increase in publications about harm from tobacco, relative to publications about treatment, and education, and to publications about environmental interventions. In 2012, 49\% of all publications were about health, while the total number of publications on environmental interventions was relatively small (10\%). Conclusion: Research output had almost doubled, in line with global trends, but is still unevenly distributed across
\end{abstract}

Europe. Although we observed a shift in European publications away from the harm of tobacco towards protecting smokers and changing the environment, the field is still dominated by publications on smoking and health.

(c) 2015 S. Karger AG, Basel

\section{Introduction}

Tobacco use is worldwide one of the main preventable causes of illness and morbidity. In line with the magnitude of the tobacco pandemic, many countries have implemented tobacco control measures. Achievements in tobacco control benefits from scientific research into the causes and consequences of the tobacco epidemic, and from research supporting the evidence for tobacco control interventions. The World Health Organisation (WHO) recognises the importance of scientific research and describes its Framework Convention on Tobacco Control (FCTC) as 'an evidence-based treaty' $[1,2]$. In article 20 of the FCTC, Parties to the Treaty are requested to 'develop and promote national research programmes at the regional and international levels in the field of tobacco control'. Having sufficient tobacco control research capacity has been recognized as an important determinant of building strong evidence-based tobacco control

\section{KARGER}

E-Mail karger@karger.com

www.karger.com/ear
(C) 2015 S. Karger AG, Basel

1022-6877/15/0221-0052\$39.50/0
Marc C. Willemsen, $\mathrm{PhD}$

Maastricht University

PO Box 616

NL-6200 MD Maastricht (The Netherlands)

E-Mail marc.willemsen@ maastrichtuniversity.nl 
policy [3]. Experts further believe that research has a significant impact on tobacco control policy adoption, especially in the field of clean indoor air laws, taxation, and smoking cessation treatment [4].

Ten years ago, it was noted that a few European countries have formal coordinated tobacco research strategies, or dedicated budgets [5] and research spending on tobacco control was low and extremely fragmented [6]. It is unclear to what extent this situation has improved. An indication of overall research productivity is the number of peer-reviewed publications [7]. To date, only one study has looked at the number of tobacco publications in Europe. Bramness et al. [8] compared the number of publications in the field of addiction, including tobacco control, between 10 European countries and the United States (US), covering the period 2001-2011 and concluded that tobacco research in the 10 European countries was lagging behind that in the United States in absolute terms. While Bramness et al. collected data from 10 countries, we sought to identify changes in tobacco control research productivity in all European countries. This was the first aim of our study.

The second aim of our study was to look at changes in the specific focus of the tobacco control research in Europe. The adoption of the WHO's FCTC in 2005 has probably drawn the attention of policy makers and researchers towards policy interventions, which are important elements of FCTC, such as awareness campaigns, smoke-free policies, restrictions on tobacco promotion, smoking cessation treatment, and tobacco taxes. One would expect less attention to research on the association between smoking and health, since this has already been firmly established. Cohen et al. [9] examined changes in worldwide research focus from the 1980 s to the 2000s, and indeed noticed a relative reduction in the number of articles focussing on health consequences of smoking. However, they did not report data specific for Europe and no data after the ratification of FCTC.

The current study set out to examine trends in research output, indicated by the number of scientific publications in 31 European countries between 2000 and 2012, and changes in research focus over time. It was expected that the volume of research publications would have increased overall, but that there would be large differences between European countries. We further expected an increase in publications focussing on FCTC population-wide interventions to the expense of publications examining the association between smoking and health.

Focus of Scientific Tobacco Control Publications between 2000 and 2012

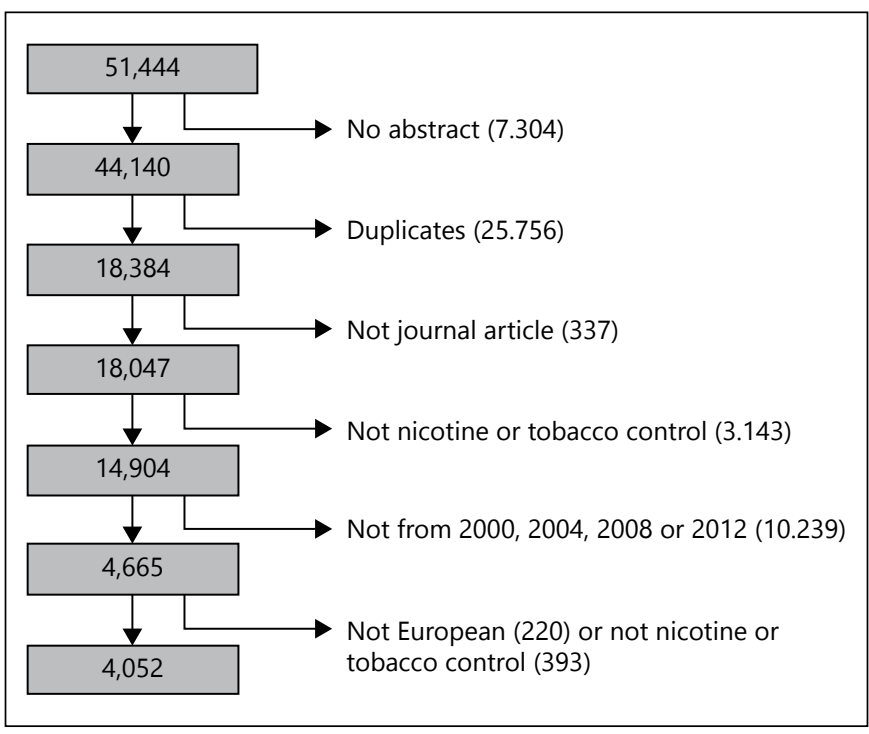

Fig. 1. Selection of publications for analysis.

\section{Methods}

We identified and counted scientific publications in the field of nicotine and tobacco research. We wanted to include a wide range of nicotine- or tobacco-related research, covering all scientific disciplines, including fields such as political sciences, economics, and sociology. Therefore, searches were performed in four databases: PubMed, Web of Science, Scopus, and PsycInfo. We selected articles that were published between 2000 until the end of 2012, used the combination of the search terms smok*, nicotine, tobacco, and cigar* in the title field, and used the affiliation or address field to select articles that had as first author a researcher from any of 31 European countries. For the United Kingdom, we used a combination of 'UK' OR 'United Kingdom' OR 'Great Britain'. The search yielded 51,444 publications, which were then imported into Endnote. In Endnote we first excluded publications (see fig. 1) that had no English abstract $(7,304)$, then removed duplicate publications $(25,756)$, further excluded publications that were not a peerreviewed journal article such as conference proceedings and reports (337), and finally removed articles that were not about a tobacco-control topic (such as fire victims, smoked fish or papers dealing with tobacco horticulture) $(3,143)$. After these exclusions, 14,904 articles related to nicotine or tobacco research remained. These 14,904 articles were used to calculate research volume per year. Research volume and research focus per country were examined for a sample of years: 2000, 2004, 2008, and 2012 (4,665 articles in total). Four years was deemed sufficient to examine the changes in research focus over the years, while keeping the study within reasonable time limits. Among the articles that were from $2000,2004,2008$ or 2012, a further 220 were found to have a first author not affiliated with a European country and were therefore excluded from further analyses and 393 were not nicotine or tobacco research related, resulting in 4,052 articles for further coding. The volume of research output was defined as the number of papers that were written per country (as indicated by the country of the first author), per year. 
Fig. 2. Number of tobacco or nicotine publications in 31 European countries, per year.

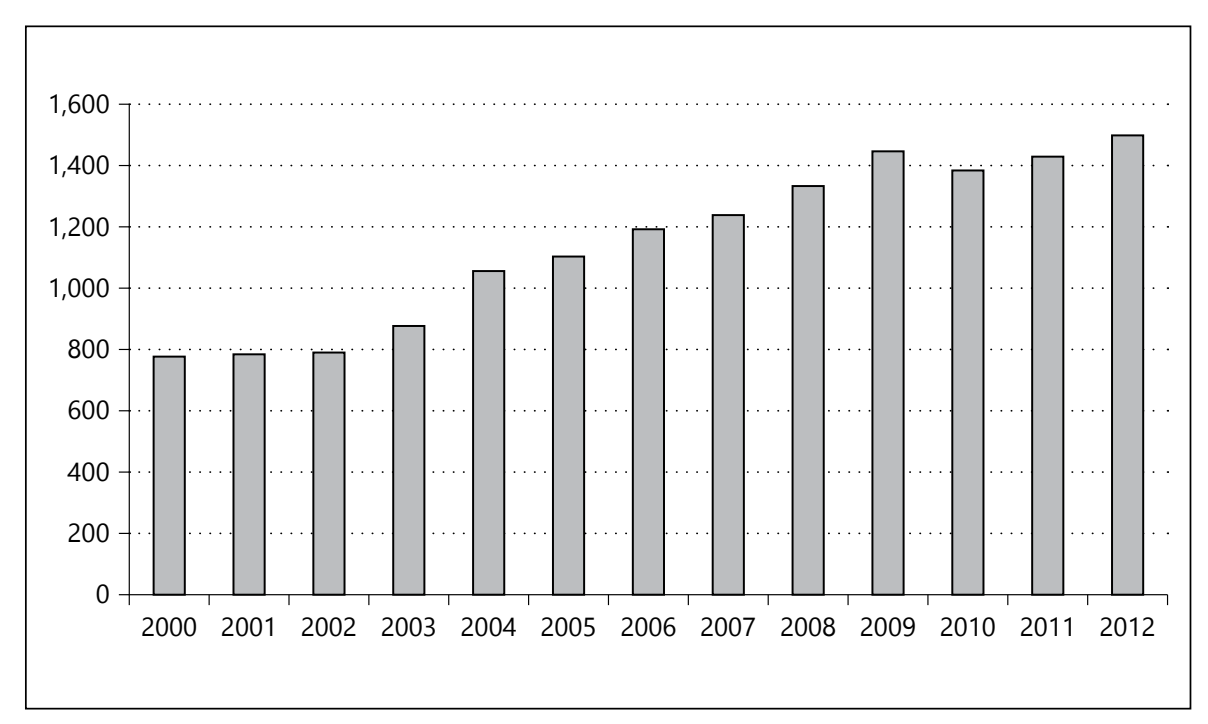

Coding was done by three trained students. Training sessions were coordinated by the two authors, using a code book that described and explained the codes in detail. After each session, the code book was further adapted and refined, until no uncertainties remained. All articles were coded as follows. First, an extra check was done on whether the paper was indeed tobacco control related (and not for example botanical). Next, the country of the first author was identified. The articles were then coded on the epidemiological framework, following the example of Cohen et al. [9]. The distinction between agent, host, environment, and vector is a wellknown way of conceptualizing the four different targets for tobacco control [10]. We defined these as follows. 'Agent' was coded when the paper focused on nicotine or tobacco devices and/or how these are associated with health, genetics, or addiction. 'Host' was coded when the paper focused on smoking and smokers' characteristics, treatment, or education. 'Environment' was coded when the paper was about environmental measures to reduce smoking, such as campaigns, taxation, advertising, and smoking bans. 'Vector' was selected when the paper had the tobacco industry as main focus of research. Next, papers were coded with respect to type of product: 1 = nicotine, 2 = tobacco or cigarette (conventional tobacco smoking product, factory made tobacco, roll-yourown, cigar, pipe, water pipe), $3=$ smokeless tobacco (including snuss, chew, non-combustible), $4=$ END's (Electronic Nicotine Delivery product or e-cigarette). Papers were also coded on the general prevention focus and type of population measure. General prevention focus was coded as: 1 = protection from second-hand smoke, 2 = smoking initiation, 3 = smoking cessation, $4=$ harm reduction (reduced smoking, using less harmful alternatives, safer cigarette), $5=$ more than one of the above, $6=$ none of the above or unclear what the focus is. The type of population measure was coded as: 1 = smoke-free laws, smoking bans, 2 = cigarette price, taxation, 3 = restrictions or bans on advertising or promotion, $4=$ health warnings on cigarette packages, plain packaging, $5=$ mass media educational campaigns, quit campaigns, $6=$ more than one of the above, 7 = none of the above or unclear what the focus is. Further, coders indicated whether the publication had a clear aim to study any of the following three topics (yes, no): smoking and health, socio-economic disparities related to smoking, pharmacotherapy for smoking cessation. Finally, coders had to indicate whether the study falls into the category of basic science (including in vitro, animal studies, preclinical research).

Three training sessions were needed before the students could code the publications uniformly. Cohen's kappa was calculated to assess the level of agreement between the students for each code category, based on 100 randomly selected publications from the database. Kappa's were excellent for country, epidemiological framework, type of product, general prevention focus, and pharmacotherapy (all 0.75 or above), and fair to good for the other categories, with socio-economic disparities having the lowest level of agreement $(\mathrm{kappa}=0.54)$.

All codes were entered in Endnote. The Endnote data file was then exported to SPSS. Data were analyzed using SPSS version 20.

\section{Results}

\section{Research Volume}

Between 2000 and 2003, the number of research articles on nicotine or tobacco produced by the 31 European countries was around 750 per year (see fig. 2). In 2003, the volume of publications started to grow with around 70 more publications each year, reaching a peak of 1,499 in 2012. This represents an annual growth rate of 5.5\%.

Table 1 presents the number of articles per country for the 4 study years. Eight countries had more than 200 publications. Most output was from the United Kingdom (849), followed by Germany (416), Spain (325), Italy (303), the Netherlands (290), Sweden (268), France (250), and Turkey (219). Together, these eight countries produced $72 \%$ of the total European volume. With the exception of the Netherlands and Sweden, these countries are 
Table 1. Number of publications per country in 2000, 2004, 2008 and $2012(\mathrm{n}=4,052)$

\begin{tabular}{|c|c|c|c|c|c|c|}
\hline & 2000 & 2004 & 2008 & 2012 & Total & $\begin{array}{l}\text { Total per } \\
\text { million } \\
\text { inhabitants* }\end{array}$ \\
\hline United Kingdom & 169 & 178 & 225 & 227 & 849 & 13.9 \\
\hline Germany & 57 & 88 & 144 & 127 & 416 & 5.0 \\
\hline Spain & 55 & 103 & 67 & 100 & 325 & 7.4 \\
\hline Italy & 58 & 68 & 87 & 90 & 303 & 5.2 \\
\hline Netherlands & 27 & 57 & 76 & 130 & 290 & 17.8 \\
\hline Sweden & 69 & 72 & 69 & 58 & 268 & 29.5 \\
\hline France & 45 & 62 & 71 & 72 & 250 & 4.0 \\
\hline Turkey & 15 & 62 & 59 & 83 & 219 & 3.1 \\
\hline Finland & 37 & 32 & 51 & 35 & 155 & 29.3 \\
\hline Poland & 19 & 29 & 30 & 31 & 138 & 3.6 \\
\hline Switzerland & 25 & 19 & 38 & 55 & 137 & 18.3 \\
\hline Denmark & 24 & 32 & 35 & 30 & 121 & 22.4 \\
\hline Norway & 16 & 29 & 30 & 31 & 106 & 22.6 \\
\hline Greece & 9 & 19 & 27 & 37 & 92 & 8.3 \\
\hline Czech Republic & 16 & 16 & 19 & 29 & 80 & 7.8 \\
\hline Austria & 14 & 16 & 12 & 15 & 57 & 7.0 \\
\hline Belgium & 10 & 5 & 21 & 15 & 51 & 4.9 \\
\hline Ireland & 6 & 11 & 11 & 15 & 43 & 10.2 \\
\hline Portugal & 0 & 9 & 16 & 11 & 36 & 3.4 \\
\hline Hungary & 3 & 11 & 6 & 15 & 35 & 3.5 \\
\hline Romania & 0 & 2 & 5 & 10 & 17 & 0.8 \\
\hline Slovakia & 4 & 5 & 3 & 2 & 14 & 2.6 \\
\hline Iceland & 2 & 1 & 4 & 3 & 10 & 33.3 \\
\hline Bulgaria & 0 & 4 & 0 & 6 & 10 & 1.3 \\
\hline Slovenia & 3 & 0 & 3 & 1 & 7 & 3.5 \\
\hline Lithuania & 0 & 1 & 2 & 4 & 7 & 2.1 \\
\hline Luxembourg & 1 & 0 & 1 & 2 & 4 & 10.0 \\
\hline Estonia & 0 & 2 & 1 & 1 & 4 & 3.1 \\
\hline Latvia & 1 & 0 & 0 & 2 & 3 & 1.4 \\
\hline Cyprus & 0 & 0 & 2 & 1 & 3 & 4.3 \\
\hline Malta & 0 & 0 & 0 & 2 & 2 & 5.0 \\
\hline All countries & 685 & 932 & 1,131 & 1,304 & 4,052 & 7.06 \\
\hline
\end{tabular}

also the largest countries in Europe, each having more than 45 million inhabitants. We then controlled for the number of inhabitants, and found that five countries produce at least 20 articles per million inhabitants. These were all Scandinavian: Iceland, Sweden, Finland, Norway, and Denmark. Finally, there were countries that scored low on both criterions, with very few publications both in absolute and relative terms: Bulgaria, Cyprus, Estonia, Latvia, Lithuania, Malta, Romania, Slovakia, and Slovenia. These had less than 20 publications in total over the 4 study years and no more than 5 publications per million inhabitants.

Focus of Scientific Tobacco Control Publications between 2000 and 2012

\section{Research Focus}

Over the years, various changes were observed in research focus. With respect to the epidemiological framework, we saw a relative reduction of research output on the 'agent' (i.e. harmful or addictive properties of nicotine or tobacco; $153 \%$ increase from 2000-2012), compared to research on aspects of the 'host' (i.e. smoking, smokers, treatment, education; $235 \%$ increase) and the 'environment' (environmental measures such as campaigns, taxation, smoking bans; $324 \%$ increase). The net effect was that the proportion of publications that has the 'agent' as main focus reduced from $61 \%$ in 2000 to $49 \%$ in 2012 (see table 2). The 'vector' (tobacco industry) remained relatively understudied: only $1 \%$ of the total.

We further examined which aspects of the 'agent' were the most studied. The vast majority was about health aspects of tobacco products (90\%), $8 \%$ was on nicotine, $2 \%$ on any type of smokeless tobacco, and $0.6 \%$ was on electronic cigarettes. While in 2000 only 4 papers dealt with smokeless tobacco $(0.6 \%)$, we found 35 in 2012 (2.7\% of publications in 2012). Publications on electronic cigarettes were virtually nonexistent until 2008 (2 articles; $0.2 \%)$. This increased to 21 articles in 2012 (1.6\% of the total in that year).

As shown in table 2 , only $8 \%$ of publications were about environmental interventions. A further inspection of these 329 articles revealed that smoking bans were most often the study topic and that this increased from 10 in 2000, 20 in 2004, 41 in 2008, to 61 in 2012. In contrast, only 26 papers across these 4 years studied mass media campaigns, 17 tobacco price or taxes, 14 advertising or tobacco promotion, and 11 health warnings on cigarette packs.

In addition to the agent, host, environment, and vector distinction, we coded general prevention focus (table 3 ). Of all papers, $30 \%$ was about smoking cessation, $6 \%$ on smoking initiation, $8 \%$ on protection from passive smoking, and $1 \%$ on harm reduction (the rest was more than one, none or unclear). The smoking cessation literature seemed to have increased relative to the other topics, from $26 \%$ of all publications in 2000, $28 \%$ in 2004 , and $30 \%$ in 2008 to $33 \%$ in 2012 . In absolute numbers, this body of literature has more than doubled (from 176 articles in 2000 to 426 in 2012).

The proportion of papers per year on any aspect of 'smoking and health', came down from 56\% in 2000, $49 \%$ in 2004 , and $50 \%$ in 2008 , to $45 \%$ in 2012 . The proportion of papers that had socio-economic disparities as the main focus increased from $2 \%$ ( 15 papers) of all publications in $2000,3 \%$ in 2004 ( 25 papers) and 2008 (36 papers) to 5\% 
Table 2. Number of articles according to epidemiological framework, per year (\%)

\begin{tabular}{lccccc}
\hline & 2000 & 2004 & 2008 & 2012 & Total \\
\hline Agent & $415(61)$ & $499(54)$ & $570(50)$ & $637(49)$ & $2,121(52)$ \\
Host & $220(32)$ & $358(38)$ & $461(41)$ & $516(40)$ & $1,555(39)$ \\
Environment & $42(6)$ & $60(6)$ & $91(8)$ & $136(10)$ & $329(8)$ \\
Vector & $8(1)$ & $15(2)$ & $9(1)$ & $15(1)$ & $47(1)$ \\
Total & $685(100)$ & $932(100)$ & $1,131(100)$ & $1,304(100)$ & $4,052(100)$ \\
\hline
\end{tabular}

Table 3. Number of articles according to general prevention focus, per year (\%)

\begin{tabular}{lccccc}
\hline & 2000 & 2004 & 2008 & 2012 & Total \\
\hline Smoking cessation & $176(26)$ & $263(28)$ & $343(30)$ & $426(33)$ & $1,207(30)$ \\
Protection from SHS & $47(7)$ & $65(7)$ & $88(8)$ & $101(8)$ & $301(8)$ \\
Smoking initiation & $38(6)$ & $74(8)$ & $72(6)$ & $66(5)$ & $250(6)$ \\
Harm reduction & $8(1)$ & $5(1)$ & $9(1)$ & $19(1)$ & $41(1)$ \\
More than one & $19(3)$ & $23(2)$ & $30(3)$ & $60(5)$ & $132(3)$ \\
None of these & $397(57)$ & $502(54)$ & $589(52)$ & $632(48)$ & $2,020(52)$ \\
\hline Total & $685(100)$ & $932(100)$ & $1,131(100)$ & $1,304(100)$ & $4,052(100)$ \\
\hline
\end{tabular}

* SHS $=$ Second hand smoke.

(69 papers) in 2012. A substantial volume of all research, around $10 \%$ was on pharmacotherapy for smoking cessation. This remained rather stable over the years. Around a quarter of all papers were in the domain of basic, preclinical research. We observed a reduction from $30 \%$ in 2000 , to $24 \%$ in 2004 and $19 \%$ in 2008 , but 2012 saw a higher proportion of research papers in this domain (29\%).

\section{Discussion}

The total volume of European scientific publications in the field of tobacco and nicotine almost doubled within 10 years. This is remarkably similar to what has been reported for scientific publications in general, with global scientific output doubling roughly every nine years [11]. The increase in volume of publications accelerated around 2003, coinciding with the European Union signing the FCTC treaty. This suggests that this event had some positive effect on research, but we cannot be sure of this. Additional data on changes in national and EU-wide funding for tobacco control research might help to elucidate this point. This obviously is an interesting area for further research.
The finding that the United Kingdom and Germany are the biggest producers of tobacco research articles in Europe was also found in previous studies for the period 1999-2003 [12] and 1900-2008 [13]. This is also in line with the United Kingdom and Germany being the two most productive EU countries with respect to overall scientific output [14]. The finding that the Scandinavian countries are most productive (when controlling for number of inhabitants) has also been found in the addiction field [8] and the public health field [15]. This has been explained by the average English proficiency, the national spending on research [16], and the cooperation between Nordic countries on tobacco control [17].

The shift in the number of European publications away from the agent of the tobacco epidemic (harmful or addictive properties of nicotine or tobacco) towards host (smoking, smokers, treatment, education) and environment follows a global trend that started three decades ago [9]. However, in absolute terms, the field is still dominated by research focussing on the agent ( $49 \%$ of all publications), while the environment $(8 \%)$ and the vector (1\%) are less often studied. This is despite the almost universal recognition that population-level strategies are the most urgently needed to combat the global tobacco epidemic $[1,18]$. In resource-constrained settings, research 
funding should contribute to interventions that have the most population impact, or are most effective among high-risk groups. When we look at the crucial FCTC interventions (smoking bans, smoking cessation support, mass media awareness campaigns, advertising and promotion restrictions, health warnings on cigarette packs, and tax increases) smoking cessation-related research was associated with the largest increase in publications (a third of all publications in 2012). We could only identify 17 papers across the 4 study years ( $0.4 \%$ of total) on tobacco taxation, while this has been identified as the most effective tobacco control measure [19].

In Europe, attention has been drawn to the fact that socio-economic inequalities in smoking are widening $[20,21]$. This recognition is reflected in our finding that the number of research papers that have socio-economic disparities as a study topic increased from around $2 \%$ of the total scientific output in 2000 to 5\% in 2012.

Although no clear increase was observed in the relative interest for harm reduction as a study topic compared to smoking cessation, we did see more studies on smokeless tobacco products and electronic cigarettes in absolute terms in 2012 compared to the other study years, which reflects increased interest to these topics $[22,23]$.

\section{Strengths and Limitations}

A major strength of our study was that we did not use samples, but identified all relevant peer-reviewed publications in the four selected study years. Our results reflect the total corpus of peer-reviewed publications, making the need to seek statistical confirmation of differences between groups redundant. Furthermore, we included no less than 31 European countries, making the results of interest to national policy makers in many European countries who can now compare their country's output to other countries and to the EU average. The only previous study that looked at tobacco control publications in Europe was restricted to 10 countries that were believed to produce as much as $95 \%$ of all publications in Europe [8]. However, our study identified Turkey, Poland and Switzerland as high-producing countries that were not included in their study. Another strength of our study was that we used multiple literature databases covering all scientific disciplines, providing a comprehensive account of nicotine and tobacco research output.

A limitation was that, for practical reasons, we restricted the coding of papers to four years (2000, 2004, 2008, 2012). While this might have been sufficient for the purpose of identifying general trends over this 13-year period, the 4 years cannot be regarded as representative for all

Focus of Scientific Tobacco Control

Publications between 2000 and 2012 years. Increases in the volume of publications triggered by major policy changes in specific years could not be captured by our data.

A second limitation of our study was that we explored trends in international peer-reviewed publications, which is not necessarily the same as trends in actual research. Research might be carried out at the national level, which is not published in peer-reviewed journals. Furthermore, we excluded potentially relevant papers if they did not have an English abstract. Since this might be the case more often in some countries than in others, a positive bias might be introduced towards countries that have a stronger tradition of publishing in English language journals. This obviously gives some advantage to the United Kingdom and Ireland, and maybe to countries such as the Netherlands and Scandinavian countries that have a population that speaks English particularly well [2]. However, this bias is becoming increasingly less important. A study looking at publications within the European Union on alcohol and drug misuse between 1976 and 2000 found that articles were published in 13 different languages, with two-thirds in English, but that the proportion of English language papers increased over time, with $85 \%$ of all publications in 1996-2000 [24]. Furthermore, publications in non-English journals were included in our study when they had an English abstract.

It should be noted that the inter-rater reliability was relatively low for socio-economic disparities, due to difficulties of identifying whether socio-economic disparities was the main research topic of a paper. Our intention was to exclude papers that only applied the socio-economic background of respondents as a confounder, but this was not always clear from the abstract. Other categories that had suboptimal inter-rater reliability were type of population measure, smoking and health, and basic science.

Finally, we did not look at the indicators of scientific quality, for example, by journal impact factor or number of citations. It was not feasible to add this information to the database because of the large number of papers in our study. Taking publication quality into account would probably reduce the relative contribution of some countries to the total, in particular, the contribution of countries that have little international collaboration. A Spanish study found that the number of citations was strongly associated with international collaboration [12].

\section{Implications}

Our study showed that the Eastern European countries Bulgaria, Estonia, Latvia, Lithuania, Romania, Slovakia, and Slovenia are particularly depleted of to- 
bacco control research. Ten years ago, an expert group concluded that research spending on tobacco control within Europe is extremely fragmented [6]. This situation seems hardly changed as these Eastern European countries are concerned, and this calls for an increase in EU tobacco control research funding and development of stronger research networks that include those countries that currently are missing the boat. Since the European Commission provides only a small amount of the overall funding for research in Europe [25], additional core funding for tobacco control research may have to come from national governments and might be included in national health plans, financed by revenue from tobacco taxes, as recommended by the WHO [26].

\section{Acknowledgements}

We would like to thank Dineke Eikelboom-Brinks, Stan Vluggen, and Linda Stommen for coding the publications and Maastricht University Library (Jos Franssen and Peter Niessen) for advising about and conducting the literature search.

\section{Competing Interests}

None declared.

\section{Funding}

This work was supported by STIVORO, the former Dutch Expert Centre on Tobacco Control.

\section{References}

1 WHO: WHO Framework Convention on Tobacco Control. Geneva, World Health Organization, 2003.

2 TNS Opinion \& Social: Europeans and Their Languages. Special Eurobarometer 386. Brussels, European Commission, 2012.

3 McDonald PW, Viehbeck S, Robinson SJ, et al: Building research capacity for evidenceinformed tobacco control in Canada: a case description. Tob Induc Dis 2009;5:12.

4 Warner KE, Tam J: The impact of tobacco control research on policy: 20 years of progress. Tob Control 2012;21:103-109.

5 McNeill A: Tobacco use and effects on health; in European Commission/ASPECT Consortium: Tobacco or Health in the European Union: Past, Present and Future. Luxembourg, Office for Official Publications of the European Communities, 2004.

6 Joossens L, Raw M, Godfrey F: The impact of tobacco-control policy on smoking in the European union; in European Commission/ ASPECT Consortium: Tobacco or Health in the European Union: Past, Present and $\mathrm{Fu}-$ ture. Luxembourg, Office for Official Publications of the European Communities, 2004.

7 Kira A, Glover M, Bullen C, et al: Publications as an indicator of increased tobacco control research productivity (quantity and quality) in New Zealand. Nicotine Tob Res 2011;13: 474-478.

8 Bramness JG, Henriksen B, Person O, et al: A bibliometric analysis of European versus USA research in the field of addiction. Research on alcohol, narcotics, prescription drug abuse, tobacco and steroids 2001-2011. Eur Addict Res 2014;20:16-22.
9 Cohen JE, Chaiton MO, Planinac LC: Taking stock a bibliometric analysis of the focus of tobacco research from the 1980s to the 2000s. Am J Prev Med 2010;39:352-356.

10 Orleans CT, Slade J (eds): Nicotine Addiction: Principles and Management. New York, Oxford University Press, 1993.

11 Bornmann L, Mutz R: Growth rates of modern science: a bibliometric analysis based on the number of publications and cited references. J Am Soc Inf Sci Tec 2014;arXiv: 1402.4578 .

12 de Granda-Orive JI, García Río F, AleixandreBenavent $\mathrm{R}$, et al: Spanish productivity in smoking research relative to world and European union productivity from 1999 through 2003 , analyzed with the science citation index. Arch Bronconeumol 2007;43:212-218.

13 Kusma B, Scutaru C, Quarcoo D, et al: Tobacco control: visualisation of research activity using density-equalizing mapping and scientometric benchmarking procedures. Int J Environ Res Public Health 2009;6:1856-1869.

14 King DA: The scientific impact of nations. Nature 2004;430:311-316.

15 Clarke A, Gatineau M, Grimaud O, et al: A bibliometric overview of public health research in Europe. Eur J Public Health 2007; 17(suppl 1):43-49.

16 Man JP, Weinkauf JG, Tsang M, et al: Why do some countries publish more than others? An international comparison of research funding, English proficiency and publication output in highly ranked general medical journals. Eur J Epidemiol 2004;19:811-817.

17 Hakala K, Waller M (eds): Nordic Tobacco Control: Towards Smokefree Societies. Copenhagen, Nordic Council of Ministers, 2003.
18 National Research Council: Ending the Tobacco Problem: A Blueprint for the Nation. Washington, DC, The National Academies Press, 2007.

19 Jha P, Peto R: Global effects of smoking, of quitting, and of taxing tobacco. N Engl J Med 2014;370:60-68.

20 Giskes K, Kunst AE, Ariza C, et al: Applying an equity lens to tobacco-control policies and their uptake in six Western-European countries. J Public Health Policy 2007;28: 261-280.

21 Kunst A, Giskes K, Mackenbach J: Socio-Economic Inequalities in Smoking in the European Union. Applying An Equity Lens to Tobacco Control Policies. Rotterdam, Erasmus Medical Center Rotterdam, 2004.

22 Pepper JK, Brewer NT: Electronic nicotine delivery system (electronic cigarette) awareness, use, reactions and beliefs: a systematic review. Tob Control 2014;23:375-384.

23 Hajek P, Etter JF, Benowitz N, et al: Electronic cigarettes: review of use, content, safety, effects on smokers and potential for harm and benefit. Addiction 2014;109:1801-1810.

24 Sánchez-Carbonell X, Guardiola E, Bellés A, et al: European Union scientific production on alcohol and drug misuse (1976-2000). Addiction 2005;100:1166-1174.

25 European Commission: Green Paper on a Common Strategic Framework for EU Research and Innovation Funding Analysis of Public Consultation. Luxembourg, Publications Office of the European Union, 2011.

26 WHO: WHO Technical Manual on Tobacco Tax Administration. Geneva, World Health Organization, 2011. 